\title{
Parabolic Dish Type Solar Cooking System with Gravity Based Solar Tracking System
}

\author{
${ }^{1}$ Mr. Prashant Raturi, ${ }^{2}$ Miss Hemlata Deolal, ${ }^{3}$ Jatin Grover, ${ }^{4}$ Amit Kumar \\ ${ }^{1,2}$ (Assistant Professor Mechanical Department Tula's Institute Dehradun Uttarakhand) \\ ${ }^{3,4}$ (Scholars Mechanical Department Tula's Institute Dehradun Uttarakhand)
}

\begin{abstract}
A mechanism for solar tracking of parabolic dish type solar cooker has been reported in this paper. The proposed mechanism of solar tracking system does not require any external source of power. The solar tracking system is based on gravity. A parabolic dish has been optimized to eliminate the need of solar tracking system along the path of sun. This paper presents the results of the tracking system. Experimental results and performance of prototype have been reported in this paper.
\end{abstract}

Keywords: solar tracking system, performance, prototype

\section{Introduction}

Many automatic tracking system have been presented by several authors, but they all require the external power source and expensive circuits like motors, batteries. The parabolic dish type cooker and box cookers with tracking system design has been studied and modified continuously in this century and different designs have been presented and extensively investigated by a number of authors (Bari, 2000; Narasimha Rao and Subramanyam, 2000; Algifriand Al-Towaie, 2001; Nahar, 2001; Purohit and Negi,2003; Mirdha and Dhariwal, 2008 Mullick, S.C Kandpal, Subodh, 1996 Muthusivagami, R.M., Velraj, R., Sethumadhavan, R., 2010).Solar cookers are generally using in the developing countries and it is beneficial for saving the fuels and it is also a renewable energy source, various plants are setup in all over the world for mass community cooking process of this type of solar cookers. This paper presents a tracking system for parabolic dish type solar cookers that does not require any external source of power. Water is stored inside a source chamber which is fixed on a certain height above the reflecting stand from the parabolic dish and a sink chamber is hinged by a hook on periphery of the parabolic dish. Both chambers are connected by a passage tube with a control valve as injector. As water is discharged at a constant rate from the source chamber, a mass of water collects in sink chamber and due to which weight of sink chamber increased by gravity effect and dish gets angular displacement with respect to time. The proposed system is simple, low cost, inspiring, easy to transport and almost maintenance cost is negligible, and in the parabolic dish system all the incident rays can focus on single point or receiver point very easily which attain a very high temperature sp it is more beneficial for cooking Operational testing and experimental results of the proposed tracking system are included in the paper.

\section{Experimental Setup with the Gravity Based Sun Tracking System}

The experimental setup of the parabolic dish type solar cooking system consist a reflector dish, reflecting stand, anodized aluminium sheets, two transparent chambers, pressure gauge, thermometer, stopper, passage tube and injector as control valve. In parabolic dish collector is made up of anodized aluminium sheets which radiates maximum solar energy at a receiver point where we put a cooking vessel for the cooking purposes. This experiment shows the tracking effect due to the action of gravity when water takes the part of source to sink chamber through passage tube. Due to this action angular displacement of dish occur with respect to time.

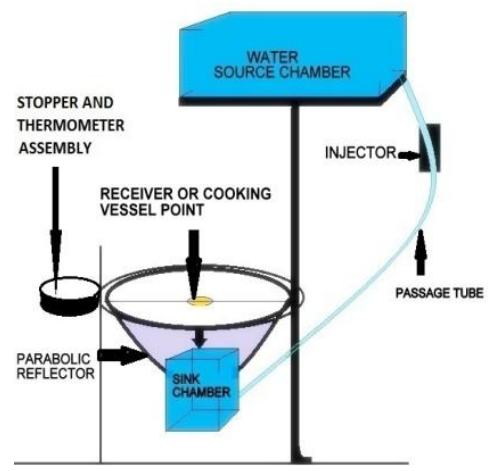

Fig.1. Schematic diagram of parabolic dish type solar cooking system with gravity based solar tracking system 


\section{Methodology of The Gravity Based Sun Tracking System}

Its phenomenon based on water injector assembly. Basically in experimental setup we take two chambers, injector, reflecting bowl, reflecting stand, passage tube and thermometer and stopper assembly.

$>$ Firstly set the reflecting face in direction of sunrise and put food vessel in cooking vessel.

$>$ Fill water in source chamber and allow water discharge in sink chamber through a passage tube having control valve.

$>$ As water falls from source chamber to sink chamber, mass of water will collects in sink chamber and weight of sink chamber will increase.

$>$ Due to collect mass of water reflecting bowl get deflected from sunrise direction with respect of track of sun.We get an angular displacement with respect to time. $\mathrm{d} \theta / \mathrm{dt}$

Where $\mathrm{d} \theta / \mathrm{dt}$ is change in angular displacement with respect to time.

$>$ It make continues concentration of sun rays at cooking vessel and convert energy of sun rays into heat energy.

$>$ Because of this tracking system maximum ray falls on reflecting surface of parabolic dish and cooking time will minimize.

\section{Operational Test Results And Discussions}

According to experimental setup, taking the volume of source chamber is 6 liter and volume of sink chamber is $3 \frac{1 / 2}{2}$ liter and makes a proper discharge of water through passage tube, according to this discharge parabolic dish track sun easily. As we know that in 1 hour sun displaces $15^{\circ}$, although this discharge follows this strategy and develops heat at receiver point where a 5 liter cooker is place. A thermometer used for measuring temperature and a pressure gauge is also set on cooker to measure pressure within cooking vessel. In first test water consider for boiling and in second test a dish (pulaoo) is made practically and experiment is successfully done. Discharge from the source chamber is,

$=1$ litre $\left(10^{-3} \mathrm{~m}^{3}\right)$ in 70 minutes $(4200 \mathrm{sec}$. $)$

$=10^{-3} \mathrm{~m}^{3} / 4200 \mathrm{sec}$

$=2.38095 \times 10^{-7} \mathrm{~m}^{3} / \mathrm{sec}$

\begin{tabular}{|l|c|c|c|}
\hline S.NO. & TIME & $\begin{array}{l}\text { TEMPERATURE } \\
\left({ }^{\circ} \mathrm{C}\right)\end{array}$ & $\begin{array}{l}\text { PRESSURE } \\
\text { Lbf/(inch })^{2}\end{array}$ \\
\hline 1 & $11: 38 \mathrm{AM}$ & $43.5^{\circ} \mathrm{C}$ & 0 \\
\hline 2 & $11: 45 \mathrm{AM}$ & $57.5{ }^{\circ} \mathrm{C}$ & 0 \\
\hline 3 & $11: 50 \mathrm{AM}$ & $70{ }^{\circ} \mathrm{C}$ & 3 \\
\hline 4 & $11: 55 \mathrm{AM}$ & $79{ }^{\circ} \mathrm{C}$ & 5 \\
\hline 5 & $12: 00 \mathrm{PM}$ & $96{ }^{\circ} \mathrm{C}$ & 5 \\
\hline 6 & $12: 05 \mathrm{PM}$ & $104.2{ }^{\circ} \mathrm{C}$ & 15 \\
\hline 7 & $12: 10 \mathrm{PM}$ & $99.7^{\circ} \mathrm{C}$ & 15 \\
\hline 8 & $12: 15 \mathrm{PM}$ & $98.4{ }^{\circ} \mathrm{C}$ & 15 \\
\hline 9 & $12: 25 \mathrm{PM}$ & $106{ }^{\circ} \mathrm{C}$ & 15 \\
\hline 10 & $12: 31 \mathrm{PM}$ & $95.1{ }^{\circ} \mathrm{C}$ & 10 \\
\hline 11 & $12: 38 \mathrm{PM}$ & $90{ }^{\circ} \mathrm{C}$ & 10 \\
\hline 12 & $12: 45 \mathrm{PM}$ & $89.5{ }^{\circ} \mathrm{C}$ & 5 \\
\hline 13 & $12: 50 \mathrm{PM}$ & $96.2{ }^{\circ} \mathrm{C}$ & 15 \\
\hline 14 & $01: 00 \mathrm{PM}$ & $98^{\circ} \mathrm{C}$ & 15 \\
\hline 15 & $01: 05 \mathrm{PM}$ & $84.1{ }^{\circ} \mathrm{C}$ & 10 \\
\hline
\end{tabular}

Table1. Testing during boiling water

\begin{tabular}{|l|l|c|c|}
\hline S.NO. & TIME & $\begin{array}{l}\text { TEMPERATU } \\
\text { RE }\left({ }^{\circ} \mathrm{C}\right)\end{array}$ & $\begin{array}{l}\text { PRESSURE } \\
\text { Lbf/(inch) })^{2}\end{array}$ \\
\hline 1 & $11: 30 \mathrm{AM}$ & $58^{\circ} \mathrm{C}$ & 0 \\
\hline 2 & $11: 37 \mathrm{AM}$ & $73.1^{\circ} \mathrm{C}$ & 0 \\
\hline 3 & $11: 43 \mathrm{AM}$ & $76{ }^{\circ} \mathrm{C}$ & 5 \\
\hline 4 & $11: 47 \mathrm{AM}$ & $80{ }^{\circ} \mathrm{C}$ & 5 \\
\hline 5 & $11: 57 \mathrm{AM}$ & $86.1{ }^{\circ} \mathrm{C}$ & 10 \\
\hline 6 & $12: 00 \mathrm{PM}$ & $81{ }^{\circ} \mathrm{C}$ & 10 \\
\hline 7 & $12: 03 \mathrm{PM}$ & $86{ }^{\circ} \mathrm{C}$ & 15 \\
\hline 8 & $12: 15 \mathrm{PM}$ & $79.2{ }^{\circ} \mathrm{C}$ & 15 \\
\hline
\end{tabular}

Table. 2 Testing during making pulaoo 


\section{Conclusion}

This article presents an excellent method for tracking the sun trajectory with parabolic dish type cooker. This mechanism does not require any external source of power. The required tracking work done is drawn by potential energy stored in source chamber. Water is discharged at a constant rate from the source chamber to sink chamber, which causes angular displacement and hence displace the parabolic dish to make maximum concentration of rays and parabolic dish displace along $45^{\circ}$ along both side, to follow the sun. The thermometer and pressure gauge give appropriate readings and the whole system has been optimized for 6 hours of cooking per day. Practical results and analysis of prototype indicate that system is working successfully.

\section{Acknowledgement}

Thanks to the administration of Tula's institute for providing us guidance in our work and the second thanks to mechanical department for their valuable discussion in our work.

\section{References}

[1]. Mirdha, U.S, Dhariwal, S.R, 2008. Design optimization of solar cooker.Renewable Energy 33 (3), 530-544.

[2]. Mullick, S.C Kandpal, Subodh, 1996. Testing of box type solar cookers:

[3]. Solar Energy, 409-413. Muthusivagami, R.M., Velraj, R., Sethumadhavan, R., 2010. Solar cookers with and without thermal storage - a review. Renewable and Sustainable Energy Reviews 14 (2), 691-701.Tiwari, G.N., 2002. Solar Energy: Fundamentals, Design, Modelling and Applications. Alpha Science International.

[4]. Tiwari, G.N., Yadav, Y.P., 1986. A new solar cooker design energy. Bari, 2000; Narasimha Rao and Subramanyam, 2000; Algifriand Al-Towaie, 2001; Nahar, 2001; Purohit and Negi,2003 